Instructions for authors, subscriptions and further details:

http://rasp.hipatiapress.com

\title{
Les Hipòtesis de Recerca Artística com a Superfícies d'Aparició. CMYK-BR::AC Universitat de Barcelona.
}

Jaume Fortuny ${ }^{1}$

1) Universidad de Barcelona. España.

Date of publication: February $3^{\text {rd }}, 2019$

Edition period: February 2019-June 2019

To cite this article: Jaume Fortuny Agramunt (2019). Les Hipòtesis de Recerca Artística com a Superfícies d'Aparició. CMYK-BR::AC Universitat de Barcelona [Review of the book]. Barcelona, Research, Art, Creation, 7 (1), 97-104. doi: 10.17583/brac.2019.4020

To link this article: http://dx.doi.org/10.17583/brac.2019.4020

\section{PLEASE SCROLL DOWN FOR ARTICLE}

The terms and conditions of use are related to the Open Journal System and to Creative Commons Attribution License (CC-BY). 
BRAC - Barcelona Research Art Creation. Vol. 7 No. 1, February 2019 pp. 97-104

(Received: 21 January 2019; Accepted: 27 January 2019; Published: 3 February 2019)

\section{Review}

C Nogué, Àlex (2018). CMYK. Clar i Fosc.

Barcelona: BR::AC Edicions. ISBN: 978-84-17238-56-8.

M Planas, Miquel (2018). CMYK. Drowning in Drawings.

Barcelona: BR::AC Edicions. ISBN: 978-84-17238-54-4

Y Descarga, Joan (2018). CMYK. Digressions intermitents. Barcelona: BR::AC Edicions. ISBN: 978-84-17238-55-1

K Josep Cerdà (2018). CMYK. Exposed Sound.

Barcelona: BR::AC Edicions. ISBN: 978-84-17238-57-5

Els quatre libres CMYK que edita el Grup de Recerca BR::AC Barcelona, Research, Art, Creation, es van presentar al Paranimf de la Universitat de Barcelona amb l'execució de l'Acció sonora Cartridge Music (Cartutx de Música) de John Cage, que el 1960 iniciava l'anomenada música nointel-lectual. Aquesta música amplifica el so dels objectes captat a través de micròfons de contacte i aconsegueix fer desaparèixer la divisió entre el plàstic i el sonor.

John Cage aconsegueix obrir-nos l'oïda als sons existents de la mateixa manera que els membres del BR::AC ens obren als sentits fent transparents els objectes de la vida real. Cage es planteja la següent qüestió: ¿Què és més musical un camió passant per davant d'una fäbrica o un camió passant pel davant d'una escola de música? Dr Miquel Planas fa de les carreteres i camins unes presències escultòriques que ens fan transparent l'espai que recorrem (Imatge 1).

2013 Hipatia Press

ISSN: 2014-8992

DOI: $10.4471 /$ brac. 2019.4020 
Dr Àlex Nogué ens fa transparents els objectes que ens envolten gràcies al seu procés de creació (Imatge 2). Desprès de la vivència d'aquest boix ja no podrem estar davant d'una xilografia al burí d'Albrecht Dürer, gràcies; y Dr Joan Descarrega ens transparenta la nostra pròpia mirada a través d'un sol "clic" de la càmera del mòbil (Imatge 3). Aquesta natura morta fa evident tot l'art des dels bodegons de Francisco de Zurbarán passant per Paul Cézanne fins arribar a Giorgio Morandi. Excepcional com no podria ser d'una altra manera, després d'haver publicat, co-autor amb Dr Àlex Nogué, un altre llibre editat per la UB que cal recordar aquí: Els límits del dibuix; on ambdós ens mostren com dibuixar una natura morta amb la mà lligada al seu gos, entre d'altres exemples (Imatge 4). Prendre consciència del gest, si, i del propi moviment dins l'entorn, d'acord; però això què ens aporta? Doncs, el que podríem anomenar una superfície d'aparició.

Aquest és el concepte clau dels libres presentats, cadascun dels quatre llibres pot ser una caixa anecoica, on no hi ha reverberació del so. Cage s'adona del so del propi cos dins d'ella.... El Grup de recerca BR::AC no pretén comunicar alguna cosa determinada, per això les seves hipòtesi de recerca conclourien en diverses superfícies d'aparició; i aquí entendrem què fa Dr Josep Cerdà, quart membre del Grup de Recerca BR::AC, amb un cap a la mà (Imatge 5), molt shakespearià... Ens va explicar com amb aquest cap artificial captava el so des de la mateixa realitat que ho fa l'espectador a través de la morfologia de l'òrgan auditiu, podem escoltar-ho amb el mòbil a través dels codis que hi ha impresos al seu llibre Exposed Sound, 2018.

Durant el concert vam escoltar molts sorolls, però no va marxar ningú. Sempre amb els llibres a la mà, els presents es van quedar i, de ben segur, en tornar a casa van adonar-se que el soroll de la nevera, el de l'aire condicionat o del mateix carrer no eren ja molestos; perquè, si prestem atenció, van definint un espai i, així, es van configurant en una representació. L'art sovint ja no sols s'expandeix, com va ho fer durant els anys 70. Ara construeix un espai i així és com es converteix en una superfície d'aparició. Havent assolit la transgressió dels nostres propis límits del sensori, el Paranimf de la Universitat de Barcelona va ser la pròpia caixa anecoica de tots els presents i a l'endemà no van prendre d'igual manera una beguda perquè ja escoltàvem cada glopada. Així és com l'argument dels llibres CYMK són les imatges, sent els textos únicament un complement conceptual i un resum de les mateixes. 


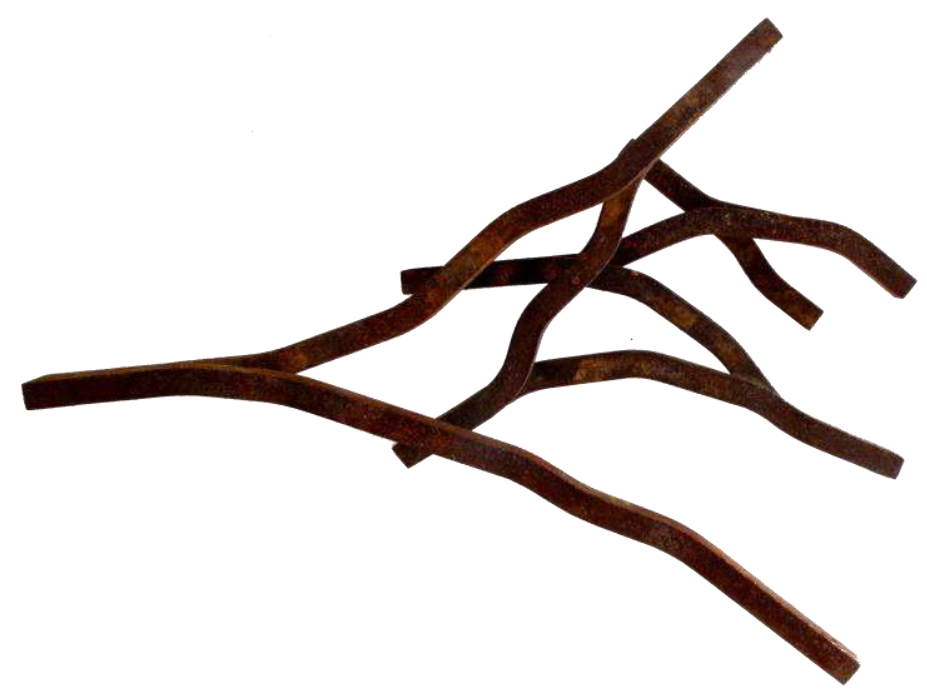

Imatge 1. Miquel Planas. L'O-43, 2017. Acer soldat i oxidat, 5x24x19 cm. 


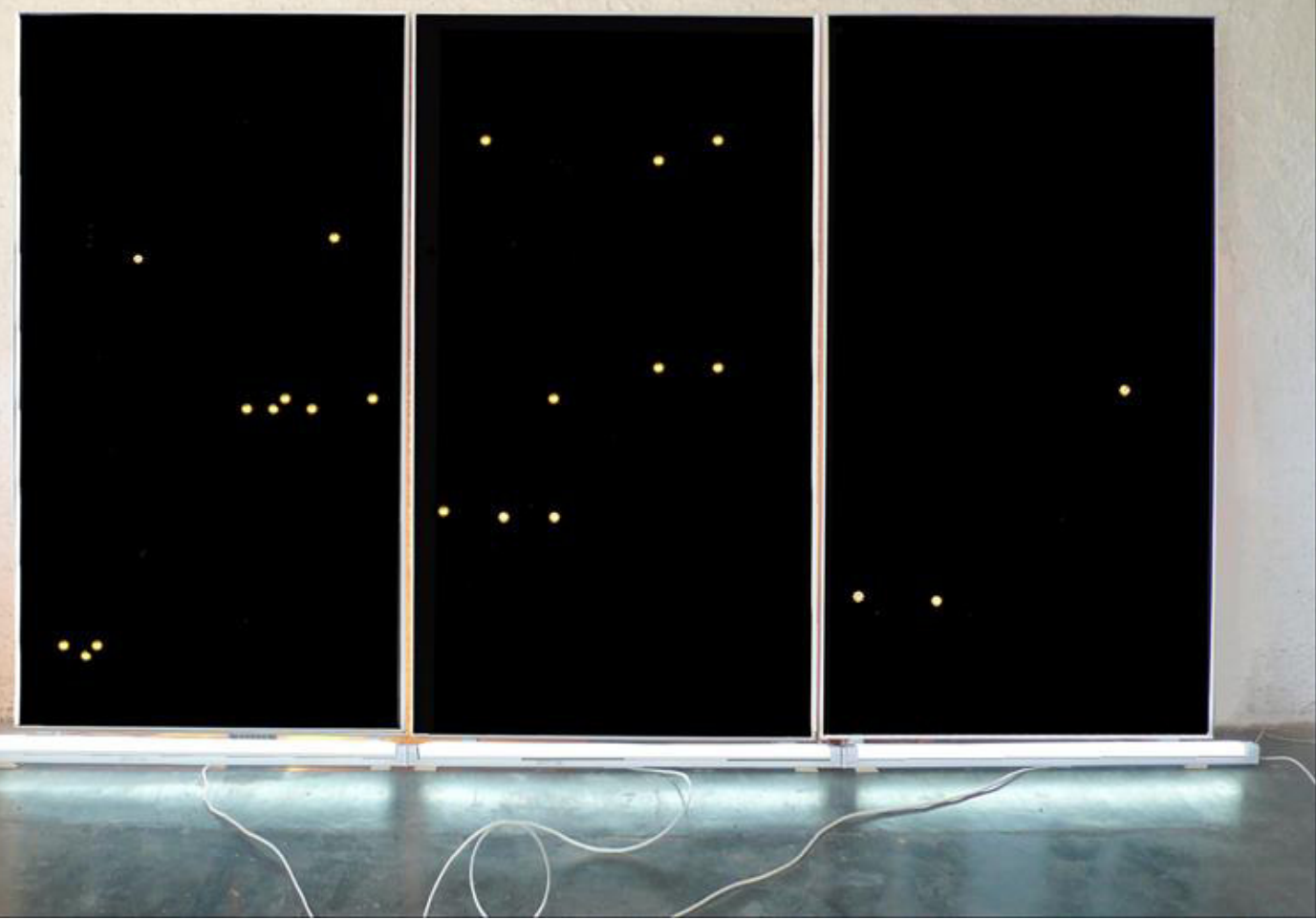

Imatge 2. Àlex Nogué. Tríptic de l'espai votiu, 2014. Instal·lació, Pintura acrílica sobre fusta, 3 barres fluorescents de $122 \mathrm{~cm}$ de llarg de $36 \mathrm{~W}-230 \mathrm{~V} 3$ focus de $100 \mathrm{w}-230 \mathrm{w}, 196,5 \mathrm{~cm}$ x $348 \mathrm{~cm}$ x $2.000 \mathrm{~cm}$ variables. 
102 Jaume Fortuny - Les Hipòtesis com a Superfícies d'Aparició

Imatge. 3. Joan Descarga. De llums i ombres, 2000. Objectes diversos i llum i ombres. 


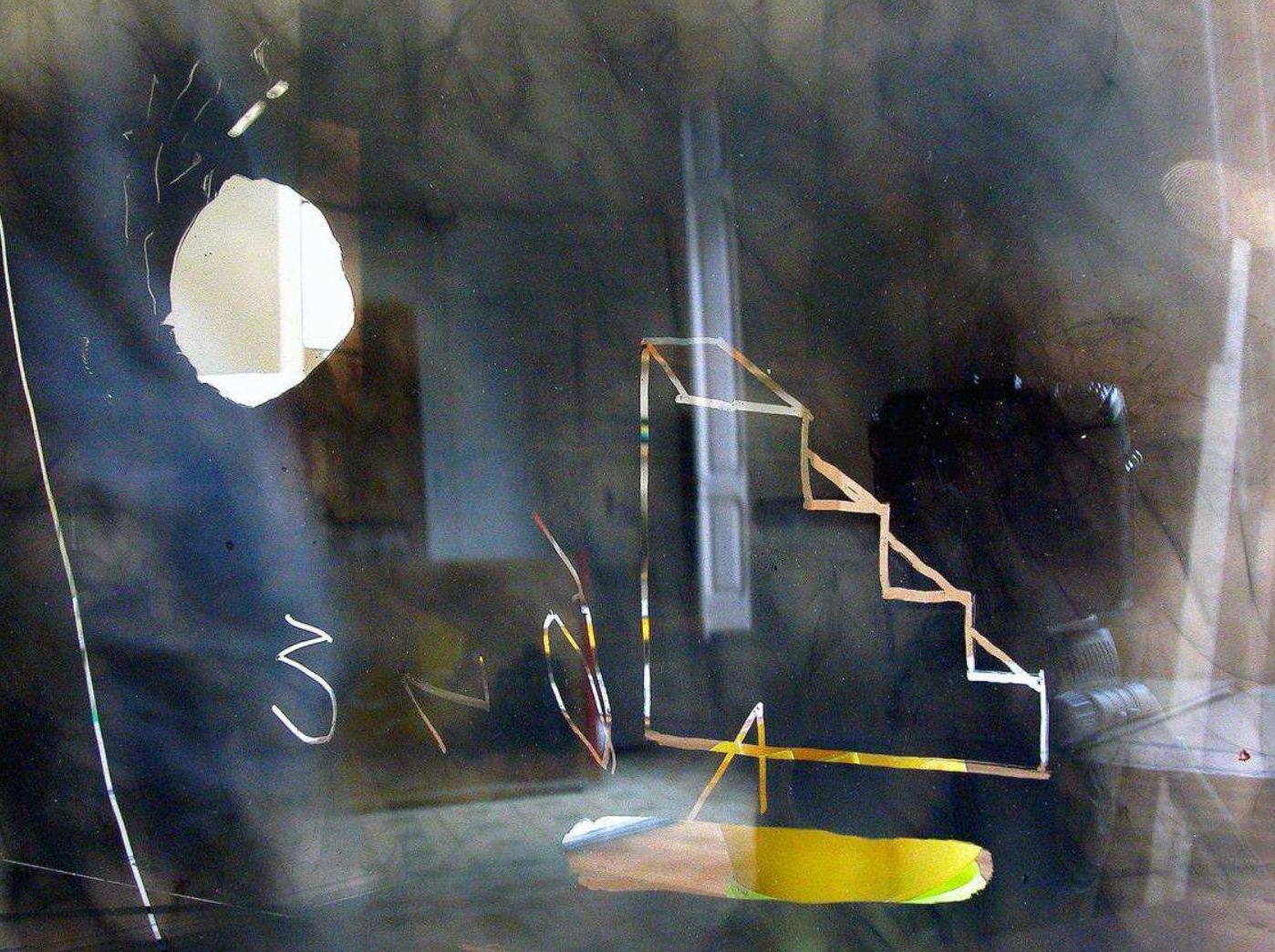

Imatge 4. Joan Descarga, 2001. Narratives de fum. Fum sobre metacrilat. 23,5 x 32 x 0,5 cm 


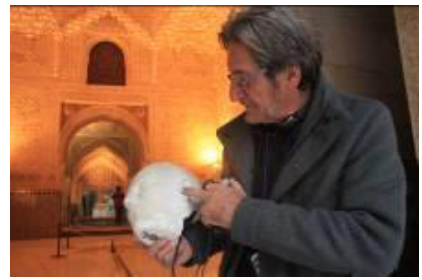

\section{http://artsonor.net}

https://twietter.com/ArtSonor

http://josepcerda.com/

https//wechat.com/josepcerda

https://issuu.com/josepcerda

https://www.instagram.com/josepcerda/
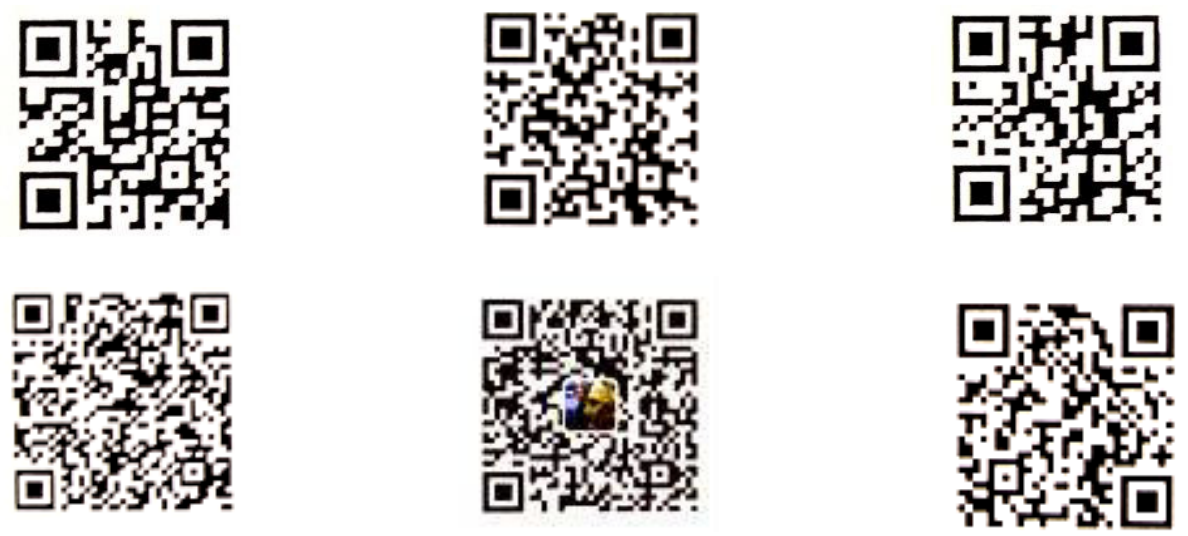

Imatge 5. Josep Cerdà. Art sonor que podem escoltar amb el mòbil a través dels codis que hi ha impresos al seu llibre CMYK Exposed Sound, 2018 editat pel BR::AC - UB. 
"Els abismes del pensament, una observació segura de la realitat present, profunditat matemàtica, exactitud física, alçada mental, agudesa intel-lectual, fantasia enyorant incansable, gaudi amant del sensori, res pot menysprear-se per aconseguir una captació vivaç i fructífera del moment; només així poden produir-se obres d'art, siguin del contingut que siguin."

Goethe

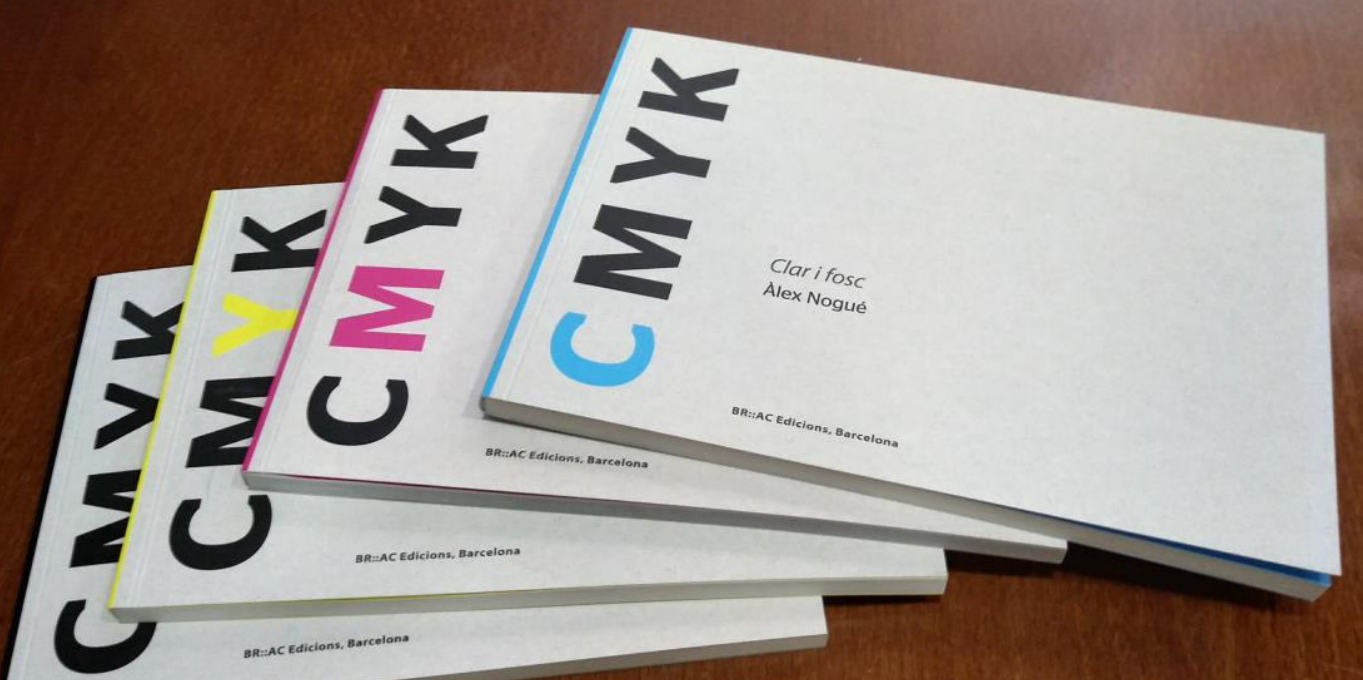

Jaume Fortuny Agramunt, Universidad de Barcelona Jaume.fortuny.agramunt@gmail.com jaume.fortuny@ub.edu 